\title{
O DESENVOLVIMENTO DE POLÍTICAS PÚBLICAS PARA O SETOR RURAL A PARTIR DA RELAÇÃO AGRICULTURA FAMILIAR, ESTADO E DEMOCRACIA
}

\author{
THE DEVELOPMENT OF PUBLIC POLICY FOR THE RURAL SECTOR \\ THROUGH THE RELATIONSHIP BETWEEN AGRICULTURE FAMILY, STATE \\ AND DEMOCRACY
}

${ }^{1}$ Marana Sotero De Sousa

\section{RESUMO}

O presente artigo objetiva analisar a agricultura familiar como mecanismo promotor do desenvolvimento de políticas públicas para o setor rural. Deste modo, pretende igualmente demonstrar que o desenvolvimento de tais políticas deu-se majoritariamente a partir das ações e programas destinados para a agricultura familiar, sendo a partir da ascensão desta atividade agrícola como categoria profissional que o Estado, juntamente com as organizações da sociedade civil, passaram a se preocupar e desenvolver políticas públicas com o objetivo de impulsionar o setor rural como um todo, o qual recebeu atenção e incentivos a partir do ano de 1990, juntamente com a consolidação da reforma gerencial do Estado, deixando de ser algo teórico e passando a fazer parte da agenda política do país. Ainda, as políticas públicas voltadas para a agricultura familiar visam combater as principais mazelas do meio rural, quais sejam, a pobreza rural, a falta de sustentabilidade e a insegurança alimentar, de modo a contribuir para alcançar o desenvolvimento deste espaço. Nesse contexto, ressalta-se que não seria possível desenvolver políticas públicas para o setor rural sem contar com a participação do Estado e dos atores sociais envolvidos agricultores, associações e sindicatos, por exemplo. Portanto, necessário se faz a união entre Estado, democracia e agricultura familiar para o desenvolvimento de tais políticas, uma vez que este tripé constitui base para a elaboração dos programas que objetivam fomentar o meio rural. Finalmente, é importante destacar que este estudo fora elaborado a partir das mais diversas fontes bibliográficas, através de análises realizadas em livros e artigos científicos sobre o tema.

Palavras-chave: Agricultura familiar, Políticas públicas, Desenvolvimento rural

\footnotetext{
${ }^{1}$ Mestranda em Direito pelo Programa de Pós-Graduação em Ciências Jurídicas da Universidade Federal da Paraíba - PPGCJ/UFPB, Paraíba (Brasil). Professora do Curso de Bacharelado em Direito das Faculdades Integradas de Patos - FIP, Belo Horizonte (Brasil). E-mail: maranasotero@ hotmail.com
} 


\begin{abstract}
This present article aims to analyze the family farming as a development mechanism to promoting public policies for the rural sector. Thus, also aims to equally demonstrate that the development of such policies took place mostly from the actions and programs for family farming, and from the rise of this agricultural activity as a professional category that the State, united with the civil society organizations, they began to worry and develop public policies in order to boost the rural sector as a whole, which received attention and incentives from the 1990's, along with the consolidation of managerial reform of the State, ceasing to be theoretical and becoming part of the political agenda of the country. Still, those public policies aimed at family farming are designed to tackle the main ills in rural areas, which are, rural poverty, lack of sustainability and the food insecurity, in order to help to achieve the development of this area. In this context, we emphasize it would not be possible to develop public policies for the rural sector without counting with the participation of State and the actors social involved - farmers, associations and trade unions, for example. Therefore it's necessary to make the union between State, democracy and family agriculture for the development of such policies, since this tripod is the basis for the development of programs aimed to foment rural areas. Finally, it is important to note that this study was drawn from the most diverse literature sources, from analyzes carried out in books and scientific articles on the subject.
\end{abstract}

Keywords: Family farming, Public policies, Rural development 


\section{INTRODUÇÃO}

O estudo a seguir objetiva analisar a influência da agricultura familiar no desenvolvimento de políticas públicas para o setor rural, levando-se em consideração, para tanto, as implicações que a relação Estado e democracia imprimem no sentido de contribuir para promover a ascensão de tais políticas.

Em outros termos, intenciona igualmente demonstrar que a própria agricultura familiar apenas obteve terreno sólido para se desenvolver a partir da implementação do Estado Democrático de Direito, tendo surgido envolta a processos sociais e democráticos. Majoritariamente, entende-se que somente após o soerguimento deste ramo da agricultura é que o Estado passou a preocupar-se com o desenvolvimento rural, e consequentemente, com a criação e incentivo de políticas públicas direcionadas para promover tal ascensão. Daí a íntima relação do tripé Estado, democracia e agricultura familiar no desenvolvimento de políticas públicas para o setor rural.

Após vivenciar as reformas patrimonialista e burocrática, consolida-se no país o modelo estatal gerencial, que emergiu a partir de 1995, sendo predominantemente marcado por processos sociais, decisões democráticas e realização de uma gestão pública compartilhada entre Estado e sociedade civil na elaboração de políticas públicas. Tal modelo administrativo propiciou a retomada de discussões ligadas ao âmbito rural, principalmente a respeito da produção de pequeno porte, reacendendo a exploração das questões referentes à agricultura familiar, terreno também favorável para o ressurgimento da preocupação e atenção para com o desenvolvimento de políticas e ações para o setor rural.

Sendo vista atualmente como uma modernização do campesinato tradicional, a agricultura familiar trata-se basicamente do cultivo de terra realizado por pequenos proprietários, consistindo em uma atividade agrícola desempenhada por um núcleo familiar.

Nesse contexto de ascensão da produção de cunho familiar, o Estado passa a se preocupar também em combater as principais mazelas que afligem e dificultam o desenvolvimento rural, quais sejam, a pobreza rural, a insegurança alimentar e a falta de sustentabilidade. Neste ponto, é possível sentir a necessidade de elaboração de políticas públicas voltadas para o desenvolvimento rural e é justamente aqui que se faz importante as ações já desenvolvidas para a agricultura familiar, que influenciam e contribuem reflexamente para obter tal desenvolvimento, bem como para guiar a criação de demais ações, políticas e programas com o intuito de realizar a promoção do setor rural. 
Assim sendo, demonstra-se que a agricultura familiar, juntamente com as ações empreendidas pelo Estado, imersos em uma esfera pública, atuam no sentido de incentivar e contribuir para o desenvolvimento de políticas públicas destinadas ao setor rural, possibilitando, igualmente, a ascensão econômica e sustentável desse espaço, elevando-o no cenário nacional e internacional.

Deste modo, ressalta-se a essencialidade da influência dos programas governamentais empreendidos na agricultura familiar para a promoção e desenvolvimento de políticas públicas no âmbito rural. A esse respeito, existe o Programa Nacional de Fortalecimento da Agricultura Familiar (PRONAF), o Programa de Aquisição de Alimentos (PAA) e o Programa Nacional de Alimentação Escolar (PNAE), que são exemplos de políticas públicas desenvolvidas para a agricultura familiar, mas que também constituem programas e ações que possibilitam o desenvolvimento do setor rural como um todo.

Ainda neste tocante, destaca-se a atuação estatal - frente as reivindicações e exigências dos atores sociais envolvidos - no desenvolvimento de políticas públicas de crédito para o setor rural. Tais políticas foram disponibilizadas inicialmente para os agricultores familiares com o intuito de fomentar a produção dos mesmos. Diante de seus resultados positivos, foram estendidas e aplicadas às demais categorias profissionais rurais justamente através do desenvolvimento de políticas públicas para o meio rural.

Além disso, os principais estudos demonstram que as políticas de crédito são umas das mais exploradas e utilizadas no meio rural exatamente por causa de seus resultados junto aos produtores e trabalhadores agrários, sendo que a maior parte dos trabalhadores do campo optam por utilizar esse tipo de política específica, vez que através da concessão do crédito é possível incentivar e aumentar a produção agrícola.

Portanto, mostra-se relevante analisar as implicações e contribuições da agricultura familiar para o desenvolvimento das políticas destinadas ao setor rural, uma vez que tal expansão iniciou-se, de fato, a partir do reconhecimento e ascensão da produção familiar como categoria profissional e econômica, elevando o meio rural e incutindo no Estado uma maior preocupação para com este ambiente.

Por fim, à título metodológico, ressalta-se que para a elaboração do presente estudo, optou-se pela pesquisa bibliográfica, através da análise dos diversos materiais a respeito do tema em questão, tais como livros e artigos científicos sobre o assunto. 


\section{A AGRICULTURA FAMILIAR E SEUS ASPECTOS}

Antigamente, a produção familiar era realizada por camponeses. A família camponesa trabalhava na lavoura e no plantio e a partir disso geravam sua própria economia e subsistência. Posteriormente, conforme as novas exigências e necessidades que o meio rural passou a demandar ao longo dos anos, houve uma espécie de modernização desse campesinato, passando agora o camponês a ser agricultor, originando a chamada agricultura familiar.

Esse ramo da agricultura emergiu no cenário brasileiro a partir dos anos 1990, até atingir status de categoria econômica em 2006, com a promulgação da Lei $\mathrm{n}^{\circ} 11.326$, de 24 de Julho do citado ano. Trata-se de uma atividade agrícola, onde a produção é gerida em núcleo familiar.

Ainda, a produção familiar é um dos temas que circundam o desenvolvimento rural, sendo uma das principais atividades que incentivaram a rediscussão de políticas públicas e mecanismos para a promoção do desenvolvimento em âmbito rural.

Para conhecer um pouco mais a respeito da importância e da íntima relação da agricultura familiar para a obtenção do desenvolvimento rural, faz-se relevante observar seu histórico, características e sua evolução como categoria econômica, fator que possibilitou o incremento e fez emergir as novos debates sobre a criação de novas políticas públicas em âmbito rural.

\subsection{Produção De Cunho Familiar: Do Campesinato À Agricultura}

Tanto o termo "camponês" como o termo "agricultura familiar" são alvos de discussões crescentes na atualidade.

Ambas as denominações são muitas vezes confundidas, principalmente pela diversidade que o termo "camponês" abrange. De outra banda, o termo "agricultura familiar" igualmente é envolto de heterogeneidade, englobando diferentes denominações, que variam de acordo com as regiões do Brasil. (BONI; BOSETT, 2013).

Sobre o campesinato tradicional, Wanderley ([S.1], [S.d], p. 45) esclarece que:

Fala-se, neste caso, de uma agricultura camponesa, cuja base é dada pela unidade de produção gerida pela família. Esse caráter familiar se expressa nas práticas sociais que implicam uma associação entre patrimônio, trabalho e consumo, no interior da família e que orientam uma lógica de funcionamento específica. Não se trata apenas de identificar as formas de obtenção do consumo, por meio do próprio trabalho, mas do reconhecimento da centralidade da unidade de produção para a reprodução da família, através das formas de colaboração dos seus membros no trabalho coletivo. 
Para Chayanov (1981), o modelo camponês se define por três características principais. A primeira diz respeito a uma interrelação entre a organização da produção e as necessidades de consumo; a segunda define o trabalho como familiar, não podendo ser analisado em termos de lucro; e a terceira característica refere-se a produção de bens de consumo.

Aliás, de acordo com Boni e Bosett (2013, p. 3), “o que torna Chayanov indispensável ao estudo do campesinato na atualidade, [...] é sua ideia de tratar o campesinato como um grupo diferenciado".

O campesinato é também marcado pela necessidade do agricultor camponês precisar obter maior resultado na sua produção, "utilizando menos recursos (terra, capital para adquirir sementes, fertilizantes, etc.), pois estes, geralmente, são insuficientes” (BONI; BOSETT, 2013, p. 5).

Posteriormente, o setor agrícola passa a sentir outras dificuldades e, consequentemente, passa a necessitar de maiores aperfeiçoamentos. O saber tradicional dos camponeses já não é mais suficiente para orientar e contribuir com o comportamento e desenvolvimento agroeconômico. Ao contrário, a atividade agrícola vem exigindo cada dia mais o domínio de conhecimentos técnicos necessários ao trabalho rural, fazendo emergir a figura do agricultor moderno. Schneider (2006, p. 171), acrescenta que "como um 'profissional como outro qualquer', o 'verdadeiro agricultor' deve demonstrar 'capacidade empresarial' para competir no mercado e encontrar na atividade agrícola a fonte da quase totalidade da renda familiar."

E diante da necessidade de mudanças e aprimoramentos para o desenvolvimento do setor rural, especificamente no que diz respeito à área agrícola, emerge a agricultura familiar.

\footnotetext{
No final dos anos 1970 e início dos anos 1980, surgem novos movimentos sociais no campo, o Movimento dos Trabalhadores Sem Terra, o Movimento dos Atingidos por Barragens, o Movimento das Mulheres Agricultoras, entre outros, que colocam em cena a problemática da distribuição de terras e a política agrícola para os "pequenos produtores". Usa-se menos o conceito de campesinato ou pequena produção e mais a caracterização de cada movimento social, como sem-terra, assentado, pequenos agricultores. Mas é na última década do século que ocorre a adoção de um conceito genérico para designar esses agricultores, é a utilização do termo "agricultura familiar" (BONI; BOSETT, 2013, p. 6).
}

Compreendido como um segmento moderno da agricultura camponesa, a referida agricultura familiar seria uma nova versão, mais atual, do campesinato tradicional. Deste modo, a produção familiar configura-se num modelo mais recente do antigo campesinato; ou seja, uma espécie de atualização pala qual passa gradativamente, onde o camponês passa a ser concebido agora como agricultor. 
Em outros termos, a produção familiar baseia-se fundamentalmente no cultivo da terra realizado por pequenos proprietários, sendo sua mão-de-obra essencialmente constituída pelo núcleo familiar. $\mathrm{O}$ enfoque passa a ser sobre a unidade social que se reproduz em regime de economia familiar e que desenvolve qualquer processo biológico sobre um pedaço de terra, situada num território com determinadas características socioeconômicas, culturais e ambientais.

Ademais, o próprio conceito de agricultura familiar guarda íntima relação hodierna, de modo que, juntamente com as próprias políticas públicas inerentes a ela, ainda tem construção muito recente no Brasil. A expressão ganhou maior destaque a partir de meados dos anos 1990, até atingir status de categoria econômica em 2006, com a promulgação da Lei nº 11.326, de 24 de Julho do citado ano.

Este setor da economia agrícola foi crescendo ao longo das gestões governamentais brasileiras em decorrência da preocupação em fortalecer os agricultores familiares, principalmente através políticas públicas, com destaque para as políticas diferenciadas de crédito/financiamento rural, como por exemplo, a nível federal, o PRONAF (Programa Nacional de Fortalecimento da Agricultura Familiar).

Conforme Picolotto (2014, p. 64), o reconhecimento da agricultura familiar no Brasil tem se dado de três formas principais:

\begin{abstract}
A primeira diz respeito ao aumento de sua importância política e dos atores que se constituíram como seus representantes (com a formação da Federação dos Trabalhadores na Agricultura Familiar (Fetraf) como organização específica de agricultores familiares e, de outro lado, com a reorientação política da Confederação Nacional dos Trabalhadores na Agricultura (Contag), que a partir de meados dos anos 1990, passou a fazer uso da categoria agricultor familiar). A segunda se refere ao reconhecimento institucional propiciado pela definição de espaços no Estado, criação de políticas públicas e pela Lei da Agricultura Familiar. E a terceira advém do trabalho de reversão das valorações negativas que eram atribuídas a este modelo de agricultura, tais como: atrasada, ineficiente e inadequada. Por meio de uma luta simbólica movida pelo sindicalismo, por setores acadêmicos e do Estado, a agricultura familiar passou a ser associada com adjetivos considerados positivos, tais como: moderna, eficiente, sustentável, solidária e produtora de alimentos.
\end{abstract}

Logo, a agricultura familiar mostra-se atualmente como uma categoria agrícola inovadora, que objetiva contribuir para o desenvolvimento rural do país. Apesar de recente, é uma atividade sustentável, que produz alimentos, gera renda, e consequentemente, incrementa o setor agroeconômico estatal. 


\title{
2.2 Agricultura Familiar E Seus Efeitos No Desenvolvimento Rural
}

Apesar dos muitos entraves, a produção em âmbito familiar vem se mostrando como um segmento que está ganhando cada vez mais importância e participação na produção rural brasileira, revelando também uma grande capacidade competitiva. Deste modo, é essencial ao desenvolvimento agroeconômico que o Estado forneça suporte e assistência técnica suficientes para o crescimento deste ramo agrícola, orientando o agricultor. Nessa perspectiva, Moreno e Flores (1992, p. 50) esclarecem:

\begin{abstract}
Reorganizar el modelo de desarrollo rural de Brasil, basado em la potencialidad de la agricultura familiar, requiere um amplio proceso de cambios institucionales destinados a proporcionar um soporte eficiente y eficaz a este tipo de productores. Entre éstas transformaciones, la construcción de una nueva asistencia técnica y extensión rural (ATER) es una de las tareas estratégicas para asegurar a los productores rurales familiares un apoyo técnico adecuado. Esta adecuación debe tener em cuenta los nuevos desafíos generados e el entorno económico caracterizado por la economía globalizada y las exigencias de competitividad de los mercados.
\end{abstract}

Daí a importância da atuação estatal tanto para o desenvolvimento da produção de cunho familiar, como para o próprio setor rural do país.

Além disso, a agricultura familiar possui grande relevância não só no setor agrícola, mas também por estar intimamente ligada a outras questões, como por exemplo, a promoção da segurança alimentar e do desenvolvimento agroeconômico e sustentável. Isso sem olvidar ainda que a cultura de cunho familiar está presente em todas as grandes produções destinadas ao mercado interno ou à exportação.

Deste modo, a produção gerida em núcleo familiar é de suma importância para combater a insegurança alimentar no Brasil, que decorre justamente da inviabilização da produção agrícola de pequeno porte, devido à falta de financiamento adequado e de incentivo à comercialização, levando a migração do campo à cidade.

As questões segurança alimentar e desenvolvimento sustentável são umas das bases para que ocorra um desenvolvimento rural correto. Assim, a agricultura familiar constitui uma ferramenta inovadora que o setor agrícola dispõe para galgar cada vez mais esse desenvolvimento do setor rural, o que igualmente permitirá o crescimento deste tipo de agricultura, tendo em vista ser uma atividade sustentável e preocupada com o meio ambiente.

Nesse contexto, a produção familiar objetiva igualmente amenizar os níveis de pobreza rural, que ainda persistem atualmente. Bonnal (2013) explica que a agricultura de subsistência sempre fora relegada desde o início da colonização do Brasil, fator que propiciou que a origem da pobreza no campo tivesse início desde muito tempo atrás. Esclarece ainda que: 


\begin{abstract}
Como se sabe, a pobreza rural no Brasil é bem mais antiga, sendo sua origem ligada à colonização portuguesa. Poder-se-ia até dizer que a formação da pobreza rural é consubstancial do modelo de colonização e de desenvolvimento econômico e social do Brasil. A marginalização da agricultura de sobrevivência iniciou-se nos primeiros tempos da colonização e não teve trégua senão até o início da década de 1990 com as medidas de previdência social, seguidas pelas políticas dirigidas à agricultura familiar. Durante mais de quatro séculos o sequestro fundiário pelas elites, a ausência de uma legislação salarial no campo e de medidas de proteção dos direitos sociais, a interdição ou enquadramento da ação político-sindical, o afastamento da agricultura familiar dos circuitos comerciais, a falta ou a escassez de serviço de educação e de saúde no meio rural fizeram com que se desenvolvessem mecanismos institucionais de aceitação e reprodução da pobreza no meio rural (BONNAL, 2013, p. 43)
\end{abstract}

Apenas com a introdução de políticas dirigidas à agricultura familiar foi possível diminuir a pobreza rural, o que consequentemente acabou por gerar efeitos positivos, na medida em que também veio a incentivar o desenvolvimento do setor agrário.

Ademais, o intuito do desenvolvimento rural é crescer de forma sustentável, promovendo "o bem-estar da sociedade rural. Neste contexto, propõe-se a formulação de estratégias e instrumentos de política para o desenvolvimento territorial em regiões principalmente rurais" (SEMINÁRIO INTERNACIONAL "DESENVOLVIMENTO RURAL E AGRICULTURA FAMILIAR”. Documento-Síntese, 2002, p. 10).

Para tanto, interessante se faz perceber a atuação do Estado e a participação dos atores sociais (envoltos num contexto democrático) na atividade familiar, de modo a compreender a influência que essa união representa para obter o desenvolvimento rural e de políticas públicas voltadas para este setor.

\title{
3 ESTADO, PARTICIPAÇÃO SOCIAL E DEMOCRACIA
}

As sucessivas reformas administrativas ocorridas no Estado brasileiro tiveram início devido à necessidade de adaptar-se aos constantes processos sociais e às exigências da população cada vez mais reivindicante de direitos.

De uma administração patrimonialista, onde prevaleciam fortemente os interesses da elite rural e dos coronéis, passamos a um modelo burocrático, onde a oligarquia agrícola tem sua força e poder de mando diminuídos, até a atual forma estatal gerencial, sendo esta a última reforma administrativa ocorrida.

A administração pública gerencial vem garantir primordialmente os interesses do cidadão e assegurar seus direitos. Nesse cenário, a democracia e a participação social fazem-se elementos fundamentais para que tais garantias sejam efetivadas e para a manutenção da própria forma gerencial de administrar, bem como do Estado Democrático de Direito. 
Ainda, é nesse panorama de reformas estatais, preocupadas com a real efetivação Estado democrático, que também inicia-se a preocupação com o desenvolvimento não só econômico, mas também do setor rural do país, que enfrenta os mais diversos problemas, desde os mais antigos e que persistem até hoje, como a má divisão das terras e a dificuldade de realização de uma reforma agrária, até a disponibilidade, ainda tímida, de políticas públicas voltadas para a expansão e incremento das atividades agrárias.

E aqui surge a agricultura familiar, uma atividade agrícola ainda recente, que tornou-se categoria econômica a partir de 2006 e que vem contribuindo para o desenvolvimento de políticas públicas no âmbito rural e da própria agricultura e, consequentemente, influenciando também no desenvolvimento deste setor do país.

Portanto, faz-se mister compreender a relação existente entre Estado, democracia e agricultura familiar, envolta a reformas administrativas, e como essa relação pode gerar consequências que auxiliem no desenvolvimento de políticas públicas para o âmbito rural brasileiro.

\subsection{Estado E Reforma Da Administração Pública}

Os modelos estatais brasileiros passaram por diversas transformações até obter a atual forma de Estado Democrático de Direito e o estilo gerencial de governança. De acordo com Bresser Pereira (1996), houve, desde os anos 1930, paralelamente às modificações que ocorreram para se chegar à atual concepção de cidadania, reformas no Estado brasileiro, ou seja, reformas na administração pública.

Deste modo, o Estado passou a encorpar diversas formas de gestão pública, que iam modificando-se a partir das mutações causadas pelos processos sociais.

O cenário político brasileiro enfrentou três reformas políticas. Inicialmente, houve uma administração pública patrimonialista, modelo estatal "que prevaleceu até as primeiras três décadas do Século XX, mas que os efeitos são sentidos até os dia atuais" (PASCARELLI FILHO, 2011, p. 23).

Tratou-se de um desenho governamental em que prevaleceu a rigidez e onde a vontade do governante era reflexo de seus interesses privados. Aqui a elite agrária e o coronelismo eram dominantes. Faoro (1984) esclarece que no modo estatal patrimonialista havia uma relação íntima e predatória dessa elite agrária governante com a administração pública brasileira. Ainda, 
Percebe-se que a administração patrimonialista caracteriza-se por um Estado centralizador, onipotente e espoliado por uma elite patrimonial, padrão que persiste por séculos. Por causa das raízes e herança desse modelo, a administração pública brasileira é caracterizada por um viés patrimonial profundo, que tem resistido, com intensidade variável, até os nossos dias (PASCARELLI FILHO, 2011, p. 24)

Posteriormente a esse modelo estatal, houve a adoção da administração pública burocrática, momento em que "há a diminuição da influência dos centros rurais nas decisões políticas-administrativas, [...] fato marcante para a mudança, lenta e gradual, da administração patrimonialista para uma administração burocratizada" (PASCARELLI FILHO, 2011, p. 25).

Consistiu em um modelo de gestão pública marcado pela impessoalidade (que buscava combater o clientelismo, tão presente na forma patrimonialista), hierarquia e formalidade, sendo esta última característica responsável pela forma rígida e centralizada que predominava no modo burocrático de administrar.

Entretanto, por revelar-se distante da realidade social e econômica, o modelo estatal burocrático começa a dar sinais de falência e despreparo frente à concomitante necessidade de modificação da forma de governar o setor público. Destarte,

\begin{abstract}
A justificativa para a reforma do aparelho do Estado não tem como único fator a crise do Estado burocrático, mas, também, a crescente escassez de recursos financeiros, as modernas regras de economia de mercado, caracterizadas pelo modelo de globalização, e o afastamento da participação popular, o que impede a legitimidade do Estado Democrático, uma vez que o poder deixa de ser a expressão da vontade coletiva e passa a representar o interesse de poucos (COELHO, 2004, p. 131).
\end{abstract}

De acordo com Bresser Pereira (1996), a reforma gerencial de 1995 surge como uma maneira de garantir e efetivar a participação popular na administração pública, sendo um modelo estatal preocupado com o cidadão e em prestar serviços públicos eficientes, que permitam o crescimento da máquina administrativa e o desenvolvimento de esferas públicas e de processos sociais.

A administração pública visa, principalmente, a democratização do Estado, uma vez que a democracia é elemento essencial para garantir a eficiência, e consequentemente, assegurar os direitos dos cidadãos.

Noutras palavras, propõe-se a reforma do Estado em nome de imperativos de eficiência, assim como de democratização do Estado e da sociedade, não apenas enquanto objetivos igualmente desejáveis, ou reciprocamente complementares, mas como mutuamente implicados. Eficiência e democracia seriam, portanto, noções que se reforçam mutuamente, no sentido de que um Estado torna-se tão mais eficiente quanto mais democrático for o seu governo e a sua administração (BENTO, 2003, p. 153) 
Logo, é no contexto da reforma administrativa gerencial de 1995 que também surge a agricultura de cunho familiar, sendo possível enxergar, através dessa modalidade agrícola, que os objetivos e prioridades desse modelo estatal contribuíram para o desenvolvimento tanto desta atividade agrária como para o desenvolvimento no âmbito rural, vez que a democracia encontrase refletida, por exemplo, nas organizações e associações de agricultores familiares, que necessitaram realizar um verdadeiro processo social e de comunicação entre os atores sociais interessados para dar o aspecto de categoria econômica à produção familiar.

Nesse sentido, pode-se compreender que a administração gerencial foi um dos mecanismos a possibilitar e assegurar os direitos e deveres da atividade econômica familiar, e por consequência, dos próprios agricultores familiares.

Finalmente, importante se faz demonstrar a relação do tripé Estado, democracia e agricultura familiar e sua relevância para a ascensão desta atividade agrícola e do setor rural.

\subsection{A Relação Estado, Democracia E Agricultura Familiar}

Neste tocante, faz-se relevante perceber a interpretação que os diversos atores sociais vinculados à agricultura familiar possuem sobre a função do Estado no desenvolvimento desta categoria.

Igualmente, é também imprescindível reconhecer a existência da democracia, a realização do processo social e a presença de um Estado Democrático que possa assegurar as garantias da agricultura familiar e contribuir para o estímulo do desenvolvimento rural.

Grisa e Schneider (2014) esclarecem que, nas últimas décadas, novas relações entre Estado e sociedade foram deflagradas. Tal fato propiciou a criação de novos espaços públicos com o surgimento de novos atores políticos, dentre eles, os agricultores familiares, com o intuito de realizar discussões sociais com fins de melhoramento desta categoria, visualizando igualmente o desenvolvimento rural. Ainda acrescentam os mencionados autores:

Neste período recente que compreende as três últimas décadas, novas relações entre Estado e sociedade civil foram estabelecidas, espaços de participação social foram criados, novos atores políticos emergiram e foram reconhecidos como sujeitos de direito, criaram-se regras e instrumentos de política pública que foram institucionalizados, e novos referenciais globais e setoriais orientaram as ações do Estado e permitiram redefinir regras e compreensões que afetaram mais ou menos as condições socioeconômicas da população, especialmente a do meio rural. Estes são alguns exemplos das mudanças iniciadas nas últimas três décadas e, em grande medida, ainda em curso. Como protagonista e objeto de muitas destas mudanças destaca-se a agricultura familiar, uma categoria social e política que passou a ser reconhecida pelo Estado brasileiro em meados de 1990 (GRISA; SCHNEIDER, 2014, p. 126). 
Abramovay e Morello (2010) ressaltam que o reconhecimento conferido à agricultura familiar ocorreu devido ao fortalecimento da democracia estar enraizado nas mais importantes transformações pelas quais passou o ambiente rural brasileiro nos últimos 20 anos, o que permitiu reduzir a pobreza de sua população e melhorar a distribuição de renda, gerando o bemestar das pessoas que vivem no campo.

O desenvolvimento rural e a promoção da atividade de cunho familiar ascenderam em momentos específicos, envoltos por mudanças políticas, administrativas e diante de eventos sociais importantes, como por exemplo, mobilizações sociais e conflitos agrários, propiciados por processos protagonizados por novos atores sociais (agricultores familiares, sindicalistas e associações rurais) e ideias nos espaços públicos, possíveis, grande parte, graças a democracia existente no nosso atual modelo estatal.

Entretanto, Grisa e Schneider (2014) alertam que ainda é necessário existir uma relação institucionalizada mais íntima entre as organizações da sociedade civil e Estado, devendo ambos estarem empenhados na realização de uma cogestão de políticas públicas, sendo necessário que os atores sociais confrontem e enfrentem, juntamente com o poder público, as restrições de acesso à terra e a melhoria da infraestrutura no meio rural, por exemplo; problemas possíveis de serem amenizados, ou mesmo sanados, através da confecção de políticas públicas, tema que será adiante abordado.

\section{A AGRICULTURA FAMILIAR NO DESENVOLVIMENTO DE POLÍTICAS PÚBLICAS PARA O SETOR RURAL}

De início, questiona-se: o que seriam políticas públicas? Qual sua importância para a promoção do setor rural? A insurgência das políticas no âmbito rural seria o resultado de um conjunto de reivindicações e de processos políticos e sociais que passaram a exigir e demonstrar a necessidade de programas que atendessem os anseios e as prioridades do campo e dos setores agrícolas, imprescindíveis para seu desenvolvimento e, consequentemente, do próprio espaço rural.

É justamente nesse cenário de reinvindicações que surge a agricultura familiar, tornandose categoria econômica e, portanto, voltando a ser discutida no âmbito rural a partir da década de 1990. Nota-se que as políticas desenvolvidas para a agricultura familiar também contribuem para o desenvolvimento rural, sendo agora preocupadas também com a sustentabilidade, questões ambientais e sociais. 


\subsection{Breve Apanhado Sobre Políticas Públicas Em Âmbito Rural}

De acordo com Silva, Dias e Silva (2014, p. 234), a discussão sobre o tema desenvolvimento rural era algo apenas teórico. Assim também eram tratadas as políticas públicas que se adequavam a esta questão. Entretanto, após diversos conflitos, reivindicações e processos sociais agrários, estes temas abandonaram o aspecto utópico e passaram a compor "uma agenda política, isto é, configurava tanto uma pauta de reivindicações, apresentadas sistematicamente ao Estado”, como também exigia do mesmo a criação de políticas públicas que abrangessem e regulassem as principais necessidades das diversas atividades desempenhadas no meio rural. Acrescentam que:

\footnotetext{
É nesse cenário de contestação política, resultado das críticas à modernização da agricultura e do difusionismo como marca da prática dos serviços públicos de extensão rural, que as organizações de movimentos sociais do campo engendraram disputas políticas em torno de modelos alternativos de produção e desenvolvimento. Neste contexto, as ONGs, junto aos movimentos sociais, foram fundamentais na luta pelos direitos dos trabalhadores rurais e na problematização dos modelos convencionais de desenvolvimento (SILVA; DIAS; SILVA, 2014, p. 233).
}

No que se refere às políticas públicas, Arcoverde (2012, p. 19) entende que "resultam da correlação de forças entre distintos interesses em disputa contextualizada pela estrutura e conjuntura política, econômica e social de cada sociedade no tempo e no espaço”. Já Grisa e Schneider (2014, p. 127) explicam que "as políticas públicas refletem, portanto, o entendimento dos grupos sociais sobre sua própria condição e sobre a sociedade em geral, bem como sobre os instrumentos necessários para aperfeiçoar esta condição”.

De acordo com Ferreira (2009), algumas características contidas nas políticas públicas auxiliam maiormente na obtenção do desenvolvimento rural, as quais fatalmente culminam também na modernização da agricultura. Seriam elas: estabelecimentos de projetos especiais e programas regionais; reestruturação da pesquisa agropecuária e da extensão rural; incremento do crédito rural, geralmente taxas de juros negativas; e subsídios para a aquisição de insumos modernos.

Via de regra, as políticas públicas que contém tais atributos são bem sucedidas na consecução do desenvolvimento rural, incrementando também os setores agrícolas, agropecuários e a agroindústria.

Cazella (2013) explica que é atitude recente do governo a descentralização de políticas públicas para o desenvolvimento rural. Tal justifica-se em virtude do realce e importância que 
o meio rural vem ganhando no país, além de ter sido constatado que é predominante o número de municípios de cunho rural existente em nosso país. Sobre isto, diz:

\begin{abstract}
As iniciativas de descentralização das políticas públicas de desenvolvimento rural são relativamente recentes no Brasil. As ações nessa direção se devem, dentre outros aspectos, à constatação de que um número significativo de municípios brasileiros apresenta características tipicamente rurais. [...] Grosso modo, cerca de um terço da população brasileira vive em regiões com características rurais (CAZELLA, 2013, p. 318).
\end{abstract}

Como dito anteriormente, as manifestações iniciais acerca de políticas públicas voltadas para o âmbito rural iniciaram a partir da agricultura familiar. Cazella (2013, p. 318) explica que "as primeiras medidas de criação de uma linha de financiamento descentralizada voltada para projetos que beneficiassem grupos de agricultores familiares começaram em meados da década de 1990, com a criação do PRONAF Infraestrutura e Serviços".

Nesse contexto, ressaltam-se algumas políticas públicas criadas para o desenvolvimento do setor rural, sendo algumas mais efetivamente destinadas aos agricultores familiares. Inicialmente, tem-se a Ação Orçamentária Apoio a Projetos de Infraestrutura e Serviços (PROINF), o Programa Nacional de Fortalecimento da Agricultura Familiar (PRONAF); o Programa de Desenvolvimento Sustentável dos Territórios Rurais (PRONAT); e também o Programa Territórios da Cidadania (PTC). De acordo com Cazella (2013, p. 319), "nesses programas, os atores sociais envolvidos foram, sobretudo, segmentos sociais ligados à agricultura familiar e, de forma específica, aos agricultores assentados pela reforma agrária”.

Adiante, demonstrar-se-á as contribuições que as políticas desenvolvidas para a agricultura familiar acarretaram para auxiliar a promover o desenvolvimento de políticas para o setor rural, bem como serão citados alguns exemplos de programas que objetivam impulsionar tanto o ambiente rural como um todo como a agricultura familiar.

\title{
4.2 A Influência Da Relação Estado, Democracia E Agricultura Familiar No Desenvolvimento De Políticas Públicas Para O Setor Rural
}

Um dos fatores que causou a discussão a respeito do desenvolvimento de políticas públicas para o setor rural foram as mudanças que a própria sociedade civil vivenciava frente à reforma administrativa gerencial.

Até a década de 90, a questão do desenvolvimento rural era pouco incentivado e explorado, sendo somente a partir do mencionado ano que houve a revitalização do tema, o qual passou a ganhar relevância, gerando novas abordagens. Logo, 


\begin{abstract}
A partir deste período, as políticas públicas e discussões teóricas sobre desenvolvimento rural reemergiram em bases inteiramente diferentes daquelas da década de 1970. Esta retomada foi fortemente influenciada pelas transformações sociais, políticas e econômicas que se operaram no âmbito do Estado, dos atores da sociedade civil e nos enfoques analíticos dos próprios estudiosos e analistas. Foram estas mudanças gerais que influenciaram as discussões especificas sobre o tema do desenvolvimento rural, desdobrando-se em políticas governamentais direcionadas para a reforma agraria, o credito para agricultura familiar, o apoio aos territórios rurais, o estimulo a ações afirmativas para mulheres, jovens, aposentados e negros (SCHNEIDER, 2010, p. 512)
\end{abstract}

Com relação ao desenvolvimento de políticas públicas voltadas para o meio rural, destacam-se as políticas de crédito, que são bastante presentes e utilizadas hodiernamente para o desenvolvimento da produção familiar, vez que tratam fundamentalmente da concessão de crédito, fornecido por instituições financeiras, através de financiamentos, com o intuito de promover o desenvolvimento econômico deste segmento agrícola.

As políticas públicas de crédito tratam de novos programas e ações direcionados para atingir o desenvolvimento econômico de determinado segmento social; contribuindo para incentivar a agricultura familiar, através da concessão de crédito, buscando efetivas transformações e melhoramentos econômicos para a produção agrícola, e consequentemente, para o setor rural.

Logo, as políticas públicas voltadas para o setor rural visam primordialmente o desenvolvimento deste tipo de ambiente, proporcionando seu crescimento de maneira sustentável, de forma a gerar cada vez mais bem-estar, emprego, renda, possibilidades e meios para que a população rural/agrícola consiga ampliar suas atividades.

Tais fatores são verdadeiros incentivadores para que o Estado realize políticas públicas, vez que os setores agrícolas estão constantemente em ascensão, necessitando da intervenção estatal, de modo a contribuir com o desenvolvimento de atividades e questões rurais, como a agropecuária, a agricultura familiar, e a reforma agrária, gerando um ciclo vicioso que só tem a contribuir para o engrandecimento e crescimento da realização de programas para o setor rural.

Ainda, de acordo com Schneider (2010), alguns fatores foram de fundamental importância para que as discussões em torno do tema desenvolvimento rural fossem despertados. Nesse sentido,

O primeiro, e talvez o mais importante, fator a ser destacado está relacionado com a trajetória das discussões em torno da agricultura familiar e de seu potencial como modelo social, econômico e produtivo para a sociedade brasileira. Por certo, tanto a agricultura familiar como os agricultores que hoje são assim denominados sempre existiram, e não se trata de uma novidade. Mas e mister reconhecer que foi na primeira metade da década de 1990 que esta noção se firmou como uma categoria política, sendo em seguida assimilada por estudiosos e por formuladores de políticas, o que lhe 
confere atualmente uma extraordinária legitimidade a tal ponto de se constituir como referência em oposição a outras noções igualmente poderosas, como a de agronegócio, por exemplo (SCHNEIDER, 2010, p. 515).

Deste modo, a agricultura familiar possui íntima relação com a questão do desenvolvimento rural e igualmente no que se refere à políticas públicas voltadas para este setor, tendo em vista ser uma das atividades agrícolas que reacenderam a preocupação e a atenção do Estado e das organizações de sociedade civil para a criação de políticas que realmente efetivem a ampliação sustentável, econômica e social do âmbito rural.

Nesse esteio, Silva, Dias e Silva (2014, p. 232) acrescentam que:

\begin{abstract}
A emergência da agricultura familiar como componente da agenda das políticas públicas de desenvolvimento rural no Brasil está relacionada a um conjunto de mudanças macroeconômicas ocorridas no final da década de 1990 que afetaram a política agrícola diretamente, provocando redução da oferta de crédito rural, eliminação de subsídios e desregulamentação do mercado agrícola interno. Esse cenário de ajuste estrutural no Brasil provocou reações diversas nas mais distintas formas de organizações no meio rural.
\end{abstract}

Neste tocante, o reconhecimento de um setor da agricultura como categoria econômica, acarretou a criação do "primeiro e mais importante programa da política direcionada à agricultura familiar: o Pronaf”' (SOUZA-ESQUERDO; BERGAMASCO, 2014, p. 206).

A criação do Programa Nacional de Fortalecimento da Agricultura Familiar (PRONAF), em 1995, foi vista como uma maneira de reconhecer a especificidade da agricultura familiar. "Este reconhecimento também garantiu a criação de uma Lei da Agricultura Familiar (Lei n. 11.326, de 2006) que define oficialmente a 'agricultura familiar' como 'categoria profissional' " (PICOLOTTO, 2014, p. 77), sendo esta mesma lei que também fornece respaldo jurídico ao PRONAF. Sobre este programa, Guanziroli (2007, p. 301).

\begin{abstract}
O PRONAF surge numa época (1995) na qual o elevado custo e a escassez de crédito eram apontados como os problemas principais enfrentados pelos agricultores, em particular os familiares. Após 10 anos de execução não cabe nenhuma dúvida que o programa se estendeu de forma considerável por todo o território nacional, ampliou o montante financiado, desenvolveu programas especiais para atender diversas categorias, assumiu a assistência técnica e reforçou a infraestrutura tanto dos próprios agricultores como dos municípios em que se encontra.
\end{abstract}

Ainda, no que se refere às políticas públicas para a agricultura familiar também destacam-se o PAA (Programa de Aquisição de Alimentos) e o PNAE (Programa Nacional de Alimentação Escolar). Nesse sentido entendem Souza-Esquerdo e Bergamasco (2014, págs. 206 e 207) ao dizer que: 


\begin{abstract}
Outro importante programa voltado para o fortalecimento da agricultura familiar brasileira é o PAA (Programa de Aquisição de Alimentos), que se dá por meio da utilização de compras governamentais como mecanismos de estímulo e de garantia de melhores preços para alimentos oriundos da agricultura familiar, criando um mercado institucional para tais produtos. Outro grande passo no sentido de promover a agricultura familiar no Brasil foi a Lei 11.947 de 16 de junho de 2009, em que se criou um elo institucional entre a alimentação escolar e a agricultura familiar local e/ou regional por meio de alterações no PNAE (Programa Nacional de Alimentação Escolar).
\end{abstract}

Além disso, passou-se a ter uma preocupação com as questões de sustentabilidade e meio ambiente quando da elaboração de políticas públicas para o desenvolvimento rural. Atualmente, pensa-se em realizar um desenvolvimento rural que seja sustentável, de modo a se preocupar com as gerações presentes e futuras.

\title{
5 CONSIDERAÇÕES FINAIS
}

O atual modelo estatal gerencial predominante em nosso país fora terreno propício para fazer surgir e aflorar as discussões e preocupações no que se refere ao desenvolvimento de políticas públicas para o setor rural. Protagonistas importantes nesse processo de soerguimento das questões rurais foram a agricultura familiar e as ações desenvolvidas pelo Estado e os atores sociais envolvidos.

A agricultura familiar, sendo uma modernização do antigo campesinato, é tida atualmente como um dos principais fatores a impulsionar o desenvolvimento de políticas públicas para o âmbito rural.

Assim sendo, a promoção de tais políticas possui íntima relação com o tripé Estado, democracia e agricultura familiar, sendo indissociáveis, vez que a criação e ampliação de políticas públicas voltadas para a área rural necessitam de uma cogestão entre poder público e os atores sociais interessados, isto é, os agricultores familiares, associações, sindicatos de agricultores e ONG's, por exemplo.

Neste caso, especificamente, observa-se o desenvolvimento de políticas para o setor rural a partir dos processos sociais realizados no âmbito da agricultura familiar, sendo esta uma das principais atividades a fomentar a discussão e a criação de ações voltadas para suprir as necessidades dos pequenos agricultores, que produzem em núcleo familiar e que representam, atualmente, uma parcela considerável, além de ser um dos principais responsáveis pela promoção deste desenvolvimento em âmbito rural.

A importância da agricultura familiar para a obtenção do incremento rural deve-se ao fato de que antes deste tipo de atividade agrícola ser reconhecida como categoria profissional e 
econômica, o desenvolvimento rural era algo que apenas se situava no campo teórico, que não era estudado nem explorado. Com o surgimento da produção de cunho familiar, começaram a surgir também as políticas públicas para sua manutenção. A principal delas, atualmente, é o Programa Nacional de Fortalecimento da Agricultura Familiar (PRONAF). É possível citar ainda o Programa de Aquisição de Alimentos (PAA), o Programa Nacional de Alimentação Escolar (PNAE) e o Programa de Desenvolvimento Sustentável dos Territórios Rurais (PRONAT). Grande parte destes programas são destinados à agricultura familiar, mas também são tidos como políticas públicas promotoras do desenvolvimento rural.

Logo, passou a existir uma maior preocupação com o incremento das atividades agrícolas e com o ambiente rural como um todo, o que ocasionou o soerguimento de políticas públicas voltadas para o seu desenvolvimento, colocando o espaço rural no cenário nacional e internacional, sendo também importante para o setor econômico interno, uma vez que gera renda.

Portanto, observar o desenvolvimento de políticas públicas em âmbito rural a partir da agricultura familiar, envolta em processos sociais e atuação estatal, mostra-se como tema que, apesar de ter emergido após a atenção dada à produção familiar, ainda é carente de estudo, necessitando de maior atenção acadêmica e de exploração pelo setor público. Com o aprofundamento das questões que envolvem o meio rural é possível inovar e criar políticas públicas mais específicas para cada atividade agrícola, conforme suas necessidades.

Nesse contexto, ressalta-se que as políticas públicas desenvolvidas para a agricultura familiar são as que mais contribuem igualmente para o desenvolvimento de políticas para o setor rural. Daí é possível perceber a importância e influência deste ramo da agricultura para o âmbito rural como um todo: as políticas destinadas para a agricultura familiar são tão intrínsecas às desenvolvidas para a área rural em geral que com elas se confundem, originando políticas públicas que atendem tanto a agricultura familiar como todo o setor rural.

\section{REFERÊNCIAS}

ABRAMOVAY, R; MORELLO, T. F. A democracia na raiz das novas dinâmicas rurais brasileiras. In: International Conference Dynamics of Rural Transformations in Emerging Economies, April 14-16, 2010, New Delhi, India.

ARCOVERDE, Ana Cristina Brito. Uma visão institucional para avaliação de políticas públicas. In: MACHADO, Nelson; et. Al. GBRSP - Gestão baseada em resultado no setor público: uma abordagem didática para implementação em prefeituras, câmaras municipais, autarquias, fundações e unidades organizacionais. São Paulo: Atlas, 2012. 
BENTO, Leonardo Valles. Governança e governabilidade na reforma do Estado: entre eficiência e democratização. São Paulo: Manole, 2003.

BONI, Valdete; BOSETT, Cleber José. Agricultura familiar e Campesinato: qual desenvolvimento rural?. In: Foro Bienal Iberoamericano de Estudios del Desarrollo, 2013. Simposio de Estudios del Desarrollo. Nuevas rutas hacia el bienestar social, económico y ambiental, 2013, Universidad de Santiago de Chile, Chile, p. 1-20. Disponível em: <http://www.iica.org.br/Docs/Publicacoes/PublicacoesIICA/DesenvRuralAgricultFamiliar_D ocSintese.pdf>. Acesso em: 11 Jul. 2015.

BONNAL, Philippe. Referências e Considerações para o estudo e a atuação dos programas de desenvolvimento territorial (PRONAT e PTC) na perspectiva da redução da pobreza em territórios rurais (capítulo 1). In: MIRANDA, Carlos; TIBURCIO, Breno (Orgs.). Políticas de desenvolvimento territorial e enfrentamento da pobreza rural no Brasil. Brasília: IICA, 2013 (Série desenvolvimento rural sustentável; v.19), 360 p., ISBN: 978-92-9248-475-0. Disponível em: <http://oppa.net.br/livros/Volume19.pdf>. Acesso em: 30 mai. 2015.

BRESSER PEREIRA, Luiz Carlos. Da administração pública burocrática à gerencial. Revista do serviço público. Brasília, v. 47, n. 1, p. 1-28, Maio, 1996. Disponível em: $<$ http://academico. direito-rio.fgv.br/ccmw/images/1/1d/Bresser.pdf >. Acesso em: 15 ago. 2011.

CAZELLA, Ademir Antônio, et. al. Ações e políticas no processo de gestão do programa territórios da cidadania: análise a partir dos estudos de caso (capítulo 9). In: MIRANDA, Carlos; TIBURCIO, Breno (Orgs.). Políticas de desenvolvimento territorial e enfrentamento da pobreza rural no Brasil. Brasília: IICA, 2013 (Série desenvolvimento rural sustentável; v.19), 360 p., ISBN: 978-92-9248-475-0. Disponível em: <http://oppa.net.br/livros/Volume19.pdf>. Acesso em: 30 mai. 2015.

CHAYANOV, Alexander V. Sobre a teoria dos sistemas econômicos não capitalistas. In: GRAZIANO DA SILVA, José; STOLCKE, Verena (Org.). A questão agrária. São Paulo: Brasiliense, 1981, p.134-163.

COELHO, Daniela Mello. Administração Pública Gerencial e Direito Administrativo. Belo Horizonte: Mandamentos, 2004.

FAORO, Raymundo. Os donos do poder. Porto Alegre: Globo, 1984.

FERREIRA, Patrícia Aparecida et al. Estado e agricultores familiares: uma análise interpretativa sobre o desenvolvimento rural no Sul de Minas Gerais. Revista de Economia e Sociologia Rural, Brasília, v. 47, n. 3, p. 769-792, Set. 2009. Disponível em: <http://www.scielo.br/scielo.php?script=sci_arttext\&pid=S010320032009000300011\&lng=en\&nrm=iso>. Acesso em: 11 Jul. 2015. 
GRISA, Catia; SCHNEIDER, Sergio. Três gerações de políticas públicas para a agricultura familiar e formas de interação entre sociedade e estado no Brasil. Revista de Economia e Sociologia Rural, Brasília, v. 52, supl. 1, p. 125-146, 2014. Disponível em: $<$ http://www.scielo.br/scielo.php?script=sci_arttext\&pid=S0103$20032014000600007 \& \operatorname{lng}=$ en\&nrm=iso>. Acesso em: 11 Jul. 2015.

GUANZIROLI, Carlos E.. PRONAF dez anos depois: resultados e perspectivas para o desenvolvimento rural. Revista de Economia e Sociologia Rural, Brasília, v. 45, n. 2, p. 301-328, Jun. 2007. Disponível em: $<$ http://www.scielo.br/scielo.php?script=sci_arttext\&pid=S010320032007000200004\&lng=en\&nrm=iso>. Acesso em: 11 Jul. 2015.

MORENO, Augusto A.; FLORES, Murilo. Mudanças Institucionais para o Apoio à Agricultura Familiar: o Caso da Extensão Rural. Sessão IV: Iniciativas para o fortalecimento da agricultura familiar, V Simpósio Latino Americano de Investigação e Extensão em Sistemas Agropecuários (IESA); V Encontro da Sociedade Brasileira de Sistemas de Produção (SBSP), realizados em Florianópolis, entre 20 e 23 de maio de 2002 (impresso e disponível no cd redistribuído no evento).

PASCARELLI FILHO, Mario. A nova administração pública: profissionalização, eficiência e governança. São Paulo: DVS Editora, 2011.

PICOLOTTO, Everton Lazzaretti. Os Atores da Construção da categoria Agricultura Familiar no Brasil. Revista de Economia e Sociologia Rural, Brasília, v. 52, supl. 1, p. 63-84, 2014. Disponível em: <http://www.scielo.br/scielo.php?script=sci_arttext\&pid=S0103$20032014000600004 \& \operatorname{lng}=\mathrm{en} \& n r m=\mathrm{iso}>$. Acesso em $11 \mathrm{Jul} .2015$.

SCHNEIDER, Sergio. A diversidade da agricultura familiar. Porto Alegre: UFRGS, 2006.

. Situando o desenvolvimento rural no Brasil: o contexto e as questões em debate. Revista de Economia Política, São Paulo, v. 30, n. 3, p. 511-531, Set. 2010 . Disponível em: <http://www.scielo.br/scielo.php?script=sci_arttext\&pid=S010131572010000300009\&lng=en\&nrm=iso>. Acesse em: 11 Ago. 2015.

\section{SEMINÁRIO INTERNACIONAL "DESENVOLVIMENTO RURAL E}

AGRICULTURA FAMILIAR”. Documento-Síntese, 2002, São Luís do Maranhão (MA), 2002. Disponível em:

<http://www.iica.org.br/Docs/Publicacoes/PublicacoesIICA/DesenvRuralAgricultFamiliar_D ocSintese.pdf >. Acesso em: 11 Jul. 2015.

SILVA, Márcio Gomes da; DIAS, Marcelo Miná; SILVA, Sandro Pereira. Relações e estratégias de (des)envolvimento rural: políticas públicas, agricultura familiar e dinâmicas locais no município de Espera Feliz (MG). Revista de Economia e Sociologia

Rural, Brasília , v. 52, n. 2, p. 229-248, Jun. 2014. Disponível em: $<$ http://www.scielo.br/scielo.php?script=sci_arttext\&pid=S0103-

$20032014000200002 \& \operatorname{lng}=\mathrm{en} \& n r m=$ iso $>$. Acesso em: 11 Jul. 2015. 
SOUZA-ESQUERDO, Vanilde Ferreira de; BERGAMASCO, Sonia Maria Pessoa Pereira. Análise sobre o acesso aos programas de políticas públicas da agricultura familiar nos municípios do circuito das frutas (SP). Revista de Economia e Sociologia Rural, Brasília, v. 52, supl. 1, p. 205-222, 2014. Disponível em:

<http://www.scielo.br/scielo.php?script=sci_arttext\&pid=S0103-

20032014000600011\&lng=en\&nrm=iso >. Acesso em: 11 Jul. 2015.

WANDERLEY, Maria de Nazareth Baudel. Agricultura familiar e campesinato: rupturas e continuidade. Texto preparado para a Aula Inaugural do primeiro semestre de 2004 a ser ministrada no CPDA/UFRJ. [S.1], [S.d], p. 43-61. Disponível em:

<http://r1.ufrrj.br/esa/art/200310-042-061.pdf>. Acesso em: 15 Jun. 2013. 